\title{
Synthesis A Flexible Conductive Film of Poly 3,4- Ethylenedioxythiophene Polystyrene Sulfonate (PEDOT: PSS) Using Spray Pyrolysis Method
}

\author{
Fadhil Muhammad Tarmidzi* and Setia Budi Sasongko
}

Department of Chemical Engineering, Faculty of Engineering, Universitas Diponegoro, Indonesia

\begin{abstract}
Popularity of conducting polymers are become widely known and researches for practical application also has been done. In order to developed a continuous process for industrial scale, we have proposed a spray pyrolysis method to synthesis a flexible conductive film of Poly(3,4-ethylenedioxythiophene) poly(styrene sulfonate) (PEDOT:PSS) on poly(ethylene terephthalate) (PET) and annealed at different temperatures and spray distances. The optimum condition that resulting a best morphology was anneal at $90^{\circ} \mathrm{C}$ and $20 \mathrm{~cm}$ distance with electrical conductivity $4.5 \mathrm{~S} / \mathrm{cm}$. It was found that annealing at temperature higher than $90^{\circ} \mathrm{C}$ will resulting a stress to a film and formed crack due to a different thermal expansion, while at the distance higher than $20 \mathrm{~cm}$ resulting a loss of PEDOT:PSS droplets. IR spectra shows that there is no any sign of PEDOT:PSS degradation even at $110^{\circ} \mathrm{C}$. SEM analysis also show that the thickness is well distributed and there is no any sign of crack formed.
\end{abstract}

Keywords: PEDOT:PSS, PET, Conductive polymer, Spray pyrolysis, flexible film

Article History: Received February 24th 2017; Received in revised form May 16 th 2018; Accepted May 20th 2018; Available online How to Cite This Article: Tarmidzi, F.M. and Sasongko, S.B. (2018) Synthesis A Flexible Conductive Film of Poly 3,4-Ethylenedioxythiophene Polystyrene Sulfonate (PEDOT:PSS) Using Spray Pyrolysis Method. Int. Journal of Renewable Energy Development, 7(2), 159-162. https://doi.org/10.14710/ijred.7.2.159-162

\section{Introduction}

Over decades, conductive polymers have been attracting great attention amongst researchers. New conductive materials are imminent to find since the optoelectronic market has been promptly expanding while the rare metal materials in earth are limited. The newest alternative, however, are based on organic materials.

Poly(3,4-ethylenedioxythiophene) poly(styrene sulfonate) (PEDOT:PSS) is one of the most successful conductive polymer for practical application (Braun \& Hegger, 1991) (Shinar, 2004) (Al-Ibrahim et al., 2005) (Saran et al., 2004) (Na et al., 2009) and becomes the most promising material due to its high mechanical flexibility. It can be formed to a thin film by various processing method, has a superior optical transparency, possesses with a good photo and electrical stability (Louwet et al., 2003) (Lang, Naujoks, \& Dual, 2009).

The most widely use method cast PEDOT:PSS film is electrospinning because its resulting a controllable diameters of fibers and also possess some unique properties (Shi et al., 2015). But, in terms of industrial purposes, electrospinning has higher cost than traditional methods (Shi et al., 2015). In order to develop an industrial scale and continuous process, spray pyrolysis represents a very simple and relatively cost-effective method. Spray has been used for several decades in the glass industry and in solar cell production to deposit electrically conducting electrodes (Perednis, 2003).

To obtain a thin, flexible, transparent, and strong material to support PEDOT:PSS film, polyethylene terephthalate (PET) becomes more convenient. Because of its high mechanical strength, PET can be folded and unfolded for many times and leaves no overt deterioration in performance.

In this paper, we present a study of developing a thin, flexible, and strong conductive polymer material using polyethylene terephthalate(PET) to support PEDOT:PSS film with spray pyrolysis method with varying annealing temperature and spray distance.

\section{Materials and Methods}

\subsection{Materials}

The PEDOT:PSS and DMSO was purchased from Sigma Aldrich having a PEDOT:PSS concentration of $1.3 \mathrm{wt} \%$ water dispersion as conductive polymer and secondary dopant is DMSO ReagentPlus ${ }^{\circledR}$ with $99.5 \%$ purity. PET sheet was purchased from PT. Asiaplast Industries with $0.32 \mathrm{~mm}$ thickness as flexible material substrate.

\footnotetext{
* Corresponding author: fadhil.m.tarmidzi@gmail.com
} 

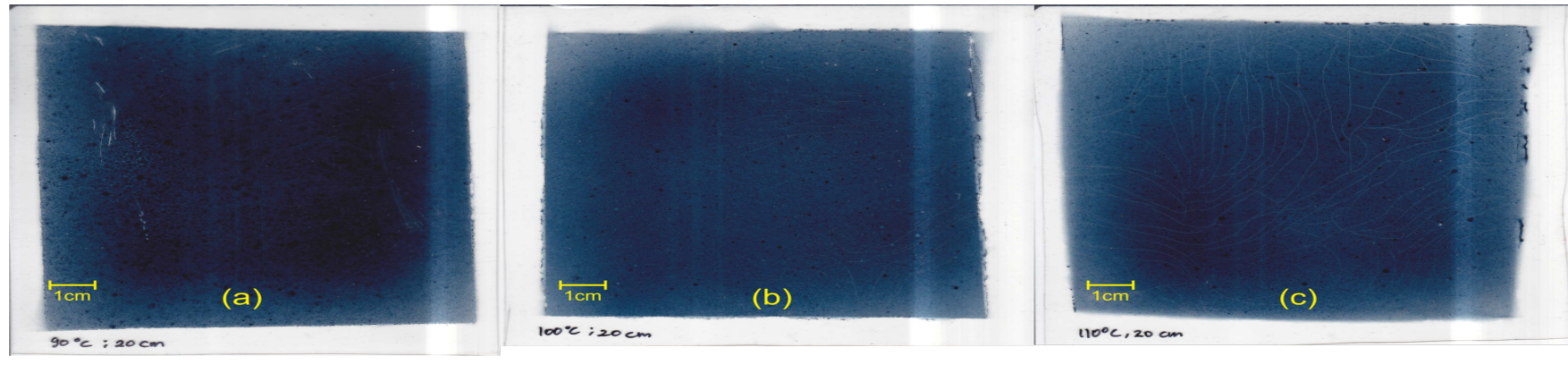

Fig. 1 PEDOT:PSS Flexible Films at $20 \mathrm{~cm}$ Spray Distance with Annealing Temperature Varies (a) $90^{\circ} \mathrm{C}$, (b) $100^{\circ} \mathrm{C},(\mathrm{c}) 110^{\circ} \mathrm{C}$

\subsection{Preparation of PEDOT:PSS flexible films}

PET substrate was used without any further pretreatment. Prior to the spray pyrolysis, a PEDOT:PSS solution was sprayed from its dispersion for $5 \mathrm{~mL}$ onto PET substrate. The machine was equipped with steel tip and brass nozzle. The distance between the tip and the substrate was varies at 10,20 , and $30 \mathrm{~cm}$. The solution was injected using 3.5 bar and $3 \mathrm{scfm}$ air flow. After deposition, the film was annealed varies at 90, 100, and $110^{\circ} \mathrm{C}$ on a hotplate until its dry completely.

\subsection{Flexible film characterization}

The conductivity of the PEDOT:PSS films was measured using a standard four-point probe method. Transmittance and absorption spectra of the films were measured using a PerkinElmer Frontier FT-IR 96772 and Shimadzu UVmini-1240 spectrophotometer. Film thickness and topography were obtained using a Phenom ProX SEM instrument at $15 \mathrm{kV}$ energy.

\section{Results and Discussion}

Spray pyrolysis technique involves spraying PEDOT:PSS solution onto a heated substrate. Droplets impact on the PET substrate, spread into disk shaped structure, and undergo thermal decomposition.

\subsection{Effect of annealing temperature}

First, we investigated the effects of annealing temperature on the physical properties of the films. Fig. 1 shows that annealing temperature can affect film morphology. Based on water boiling point, it is shows that vaporizing water as solvent on higher boiling point (Fig. 1c) make PEDOT:PSS film cracked. But, with the annealing temperature at $90^{\circ} \mathrm{C}$ (Fig. 1a) shows that the film morphology is good, crack also not formed.

A research proposed the following processes that occur with the increasing substrate temperature from the lowest to highest temperature regime (Vigui \& Spitz, $1975)$. In this case, lowest temperature regime $\left(90^{\circ} \mathrm{C}\right)$ is the suitable temperature for annealing PEDOT:PSS on PET substrate the film not formed any crack, it makes the film can be used for any further purposes, applying recoating will perform a better morphology. For solar cell purposes, it can be done by coating another layer so that another layer will not penetrate in PEDOT:PSS film. At $100^{\circ} \mathrm{C}$, a thinly crack formed due to film stress and at $110^{\circ} \mathrm{C}$ the crack formed clearly, while using glass as substrate, annealed temperature at $150^{\circ} \mathrm{C}$ was not reported (Im et al., 2008).

Stresses in thin film can cause by intrinsic stress that arise during deposition process or thermal stresses due to changes in temperature. The mechanisms of intrinsic stress are not well quantified and most estimates of intrinsic stress levels are obtained by experimental measurement (Hutchinson \& Jensen, 1996). We believe that the film cracks formed is more because of thermal stress. It is cause from the loss of water and make thermal expansion of PEDOT:PSS $\left(49.92 \times 10^{-6} \mathrm{~K}^{-1}\right.$ (Khan \& Brunswick, 2017)) and PET (80x10-6 $\mathrm{K}^{-1}$ (Covered, 2003)) mismatch, so the annealed film expands at a different rate than the substrate with almost 1.6 times slower than PET. This also can be formed because the film is too thick. As reported in glass substrate, soda lime glass has a softening point beyond $550^{\circ} \mathrm{C}$, while PET has heat deflection temperature about $115^{\circ} \mathrm{C}$ (Covered, 2003). Thus, annealing PEDOT:PSS film on glass substrate at $150^{\circ} \mathrm{C}$ still can be achieved without any deformation of the glass, meanwhile at annealing temperature $110^{\circ} \mathrm{C}$ on PET, its reached closes to its softening point which will be the reason crack is formed.

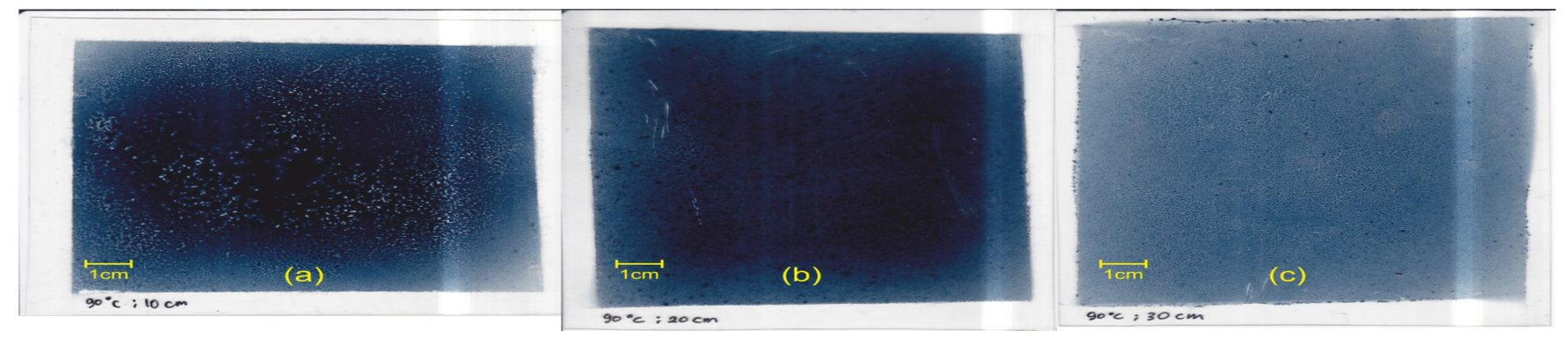

Fig. 2 PEDOT:PSS Flexible Film at 90 ${ }^{\circ} \mathrm{C}$ Annealing temperature with Spray Distance varies (a) $10 \mathrm{~cm}$, (b) $20 \mathrm{~cm}$, (c) $30 \mathrm{~cm}$ 
The other possibility is the annealing ambient temperature. Thin films are very sensitive to temperature gradient of substrate. Materials naturally will expand when heated and contract when cooled. Also, the temperature outside and around the droplet can affects the deposition (Yu \& Liao, 1998). In this case, PEDOT:PSS film is contact with ambient condition, while PET substrate is contact with annealing temperature, it force PET substrate expanded and PEDOT:PSS film contracted. Thus, resulting thermal differential between interior film and exterior film that lead to cracking.

\subsection{Effect of spray distances}

Spray distance affect the transportation mechanism of PEDOT:PSS droplets. In order to get a dense film, the droplets must transport into the substrate before forming particles before reaching the surface. Fig. 2 shows that spray distance can affect PEDOT:PSS film growth. At 10 $\mathrm{cm}$ distance (Fig. $2 \mathrm{a}$ ) shows that there is a contact between the PEDOT:PSS droplets and PET substrate. It resulting an uneven distribution of droplets and make the film thickness not well distributed. When the droplet impact onto the substrate, it will stick to the substrate and splash because its terminal velocity is too high. At $20 \mathrm{~cm}$ distance (Fig 2b) shows that the film is concentrated in the middle of PET substrate. Also, at this distance, the distribution of film is well enough with no prove of uneven droplets distribution as the result of the spreading of impacted droplets. At $30 \mathrm{~cm}$ distance (Fig 3b), most of the droplets is flew away as the result of thermophoretic force and minimize the amount of the droplets that can be attached to the film and resulting a very thin layer.

There are some forces that can affect the film growth, such as gravitational, thermophoretic, and stokes force (Sears \& Gee, 1988). The forces can determine the trajectory of the droplets and evaporation. Gravitational force pushes the droplets into the substrate and make the droplets accelerate, while thermophoretic force neglected the gravitational force by pushing the droplets away from the substrate. Thermophoretic effect cause the droplets pushed away by the gas molecules from vaporized solvent on the hot substrate. The different temperature from the hotter side and the cooler side make the droplet rebound with higher kinetic energy. Thus, the gravitational and thermophoretic forces can be sums as stokes force.

\subsection{IR Spectra characterization}

As shown in Fig. 4, the IR spectra of the PEDOT:PSS film in different annealing temperature is not having any different. The spectrum obtained for the PEDOT:PSS film is similar to those reported in the literature (Zhao, Jamal, Zhang, Wang, \& Abdiryim, 2014). The bands near 1513 and $1296 \mathrm{~cm}^{-1}$ are assigned to asymmetric stretching mode of $\mathrm{C}=\mathrm{C}$ and inter-ring stretching mode of $\mathrm{C}-\mathrm{C}$, respectively. 1170,1127 , and $1033 \mathrm{~cm}^{-1}$ are attributed to the $\mathrm{C}-\mathrm{O}-\mathrm{C}$ bending vibration in ethylenedioxy group. The band near $586 \mathrm{~cm}-1$ is assigned to oxyethylene ring deformation, while the band near 480 and $428 \mathrm{~cm}^{-1}$ are attributed to $\mathrm{C}-\mathrm{O}-\mathrm{C}$ deformation. It is observed that there is no new peak presence. Thus, there are no any indication of PEDOT:PSS degradation at $110^{\circ} \mathrm{C}$.

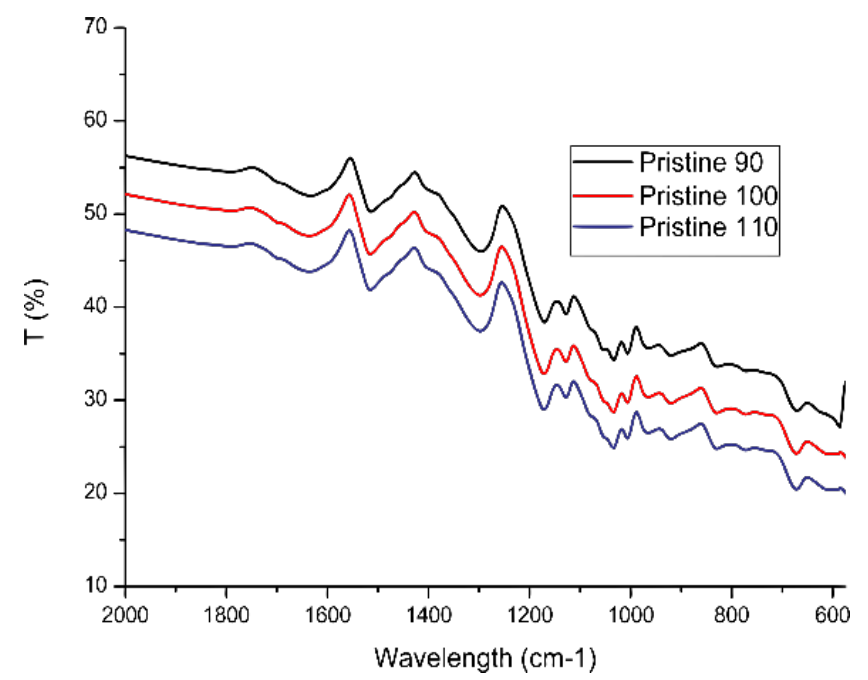

Fig. 3 IR Spectra of PEDOT:PSS Films

\subsection{SEM characterization}

Figures 4 show the SEM image of PEDOT:PSS flexible film at annealing temperature $90^{\circ} \mathrm{C}$ and $20 \mathrm{~cm}$ spray distance. As depicted in Figure 4a, PEDOT:PSS film display that the film thickness has a good distribution with approximately $55 \mu \mathrm{m}$ thick of PEDOT:PSS. The boundary layer between PET substrate and PEDOT:PSS film was formed due to cutting process. It is also show that the film is attached to PET substrate. In figure $4 \mathrm{~b}$ shows that PEDOT:PSS film also has a smooth surface area. There is also found that there is no crack formed due to thermal stress which means the operation condition can be acceptable. A damage part is also found due to cutting process and show that the film is not a scratch resistance.

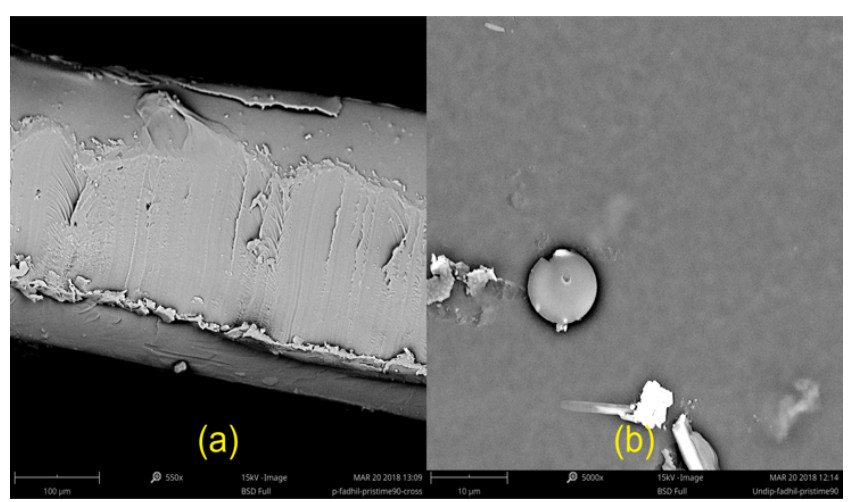

Fig. 4 SEM Image of PEDOT:PSS Flexible Film (a) Cross Section Image (b) Surface Area Image

\subsection{Film electrical conductivity}

The room electrical conductivity of PEDOT:PSS flexible film is affected by annealing temperature. At $90^{\circ} \mathrm{C}$, the conductivity is $4.5 \mathrm{~S} / \mathrm{cm}$, while at higher temperature, its conductivity dropped to $2.3 \mathrm{~S} / \mathrm{cm}$. It is noted that the electrical conductivity of PEDOT:PSS solution is $1 \mathrm{~S} / \mathrm{cm}$. There is only a slight increase in electrical conductivity from liquid form to solid form. The drop of conductivity is probably because of the film cracking that make the electron flow cannot be maximized. 


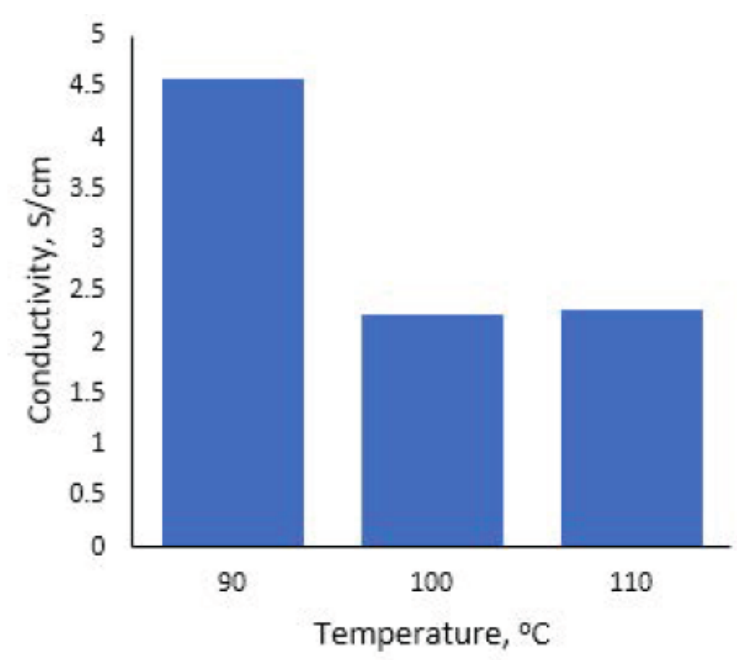

Fig. 5 PEDOT:PSS Films Electrical Conductivity

\section{Conclusion}

Developing a flexible film of PEDOT:PSS has been done using spray pyrolysis method. Pyrolysis method at annealing temperature of $90^{\circ} \mathrm{C}, 100^{\circ} \mathrm{C}$, and $110^{\circ} \mathrm{C}$ and spray distance at $10 \mathrm{~cm}, 20 \mathrm{~cm}$, and $30 \mathrm{~cm}$ were examined. A crack due to thermal expansion difference was found at annealing temperature above $100^{\circ} \mathrm{C}$. A suitable condition to anneal PEDOT:PSS film on PET substrate are at annealing temperature $90^{\circ} \mathrm{C}$ and $20 \mathrm{~cm}$ spray distance with electrical conductivity is $4.5 \mathrm{~S} / \mathrm{cm}$. According to the IR spectra, annealing up to $110^{\circ} \mathrm{C}$ was not found any indications of PEDOT:PSS degradation. SEM analysis also found that there is no any indication of cracking formation at $90^{\circ} \mathrm{C}$.

\section{References}

Al-Ibrahim, M., Roth, H. K., Schroedner, M., Konkin, A., Zhokhavets, U., Gobsch, G., Scharff, S., \& Sensfuss, S. (2005). The influence of the optoelectronic properties of poly(3-alkylthiophenes) on the device parameters in flexible polymer solar cells. Organic Electronics: Physics, Materials, Applications, 6(2), 65-77.

Braun, D., \& Hegger, A. J. (1991). Visible light emission from semiconducting polymer diodes. Appl. Phys. Lett. 58, 1982

Goodfellow. (2003). Polyethylene Terephthalate Polyester (PET, PETP) - Properties and Applications - Supplier Data.

Hutchinson, J. W., \& Jensen, H. M. (1996). Stresses and Failure Modes in Thin Films and Multilayers. Division of Engineering and Applied Sciences. Harvard University.

Im, S. G., Kusters, D., Choi, W., Baxamusa, S. H., van de Sanden, M. C. M., \& Gleason, K. K. (2008). Conformal coverage of poly(3,4-ethylenedioxythiophene) films with tunable nanoporosity via oxidative chemical vapor deposition. ACS Nano. 2 (9), 1959-1967

Khan, N. Z., \& Brunswick, N. (2017). Modeling and Simulation of Organic MEM Relay for Estimating the Coefficient of Thermal Expansion of PEDOT:PSS. The State of University of New Jersey.

Lang, U., Naujoks, N., \& Dual, J. (2009). Mechanical characterization of PEDOT: PSS thin films. Synthetic Metals, 159(5-6), 473-479.

Louwet, F., Groenendaal, L., Dhaen, J., Manca, J., Van Luppen, J., Verdonck, E., \& Leenders, L. (2003). PEDOT/PSS: synthesis, characterization, properties and applications. Synthetic Metals, 135-136, 115-117.
Na, S., Wang, G., Kim, S., Kim, T., Oh, S., Yu, B., Lee, T., \& Kim, D. (2009). Evolution of nanomorphology and anisotropic conductivity in solvent-modified PEDOT: PSS films for polymeric anodes of polymer solar cells. Journal of Materials Chemistry, 19, 9045-9053.

Perednis, D. (2003). Thin Film Deposition by Spray Pyrolysis and the Application in Solid Oxide Fuel Cells. ETH Zurich. https://doi.org/10.3929/ethz-a-004637544.

Saran, N., Parikh, K., Suh, D.-S., Muñoz, E., Kolla, H., \& Manohar, S. K. (2004). Fabrication and Characterization of Thin Films of Single-Walled Carbon Nanotube Bundles on Flexible Plastic Substrates. Journal of the American Chemical Society. 26 (14), 4462-4463

Sears, W. M., \& Gee, M. A. (1988). Mechanics of film formation during the spray pyrolysis of tin oxide. Thin Solid Films., 165(1), 265-277

Shi, X., Zhou, W., Ma, D., Ma, Q., Bridges, D., Ma, Y., \& Hu, A. (2015). Electrospinning of Nanofibers and Their Applications for Energy Devices. Journal of Nanomaterials, 2015, Article ID 140716.

Shinar, J. (2004). Organic Light-Emitting Devices: A Survey. Iowa State University.

Vigui, J. C., \& Spitz, J. (1975). Chemical vapor deposition at low temperatures. J. Electrochem. Soc.: SOLID-STATE SCIENCE AND TECHNOLOGY, 122(4), 585-588.

Yu, H.-F., \& Liao, W.-H. (1998). Evaporation of solution droplets in spray pyrolysis. International Journal of Heat and Mass Transfer, 41(8-9), 993-1001.

Zhao, Q., Jamal, R., Zhang, L., Wang, M., \& Abdiryim, T. (2014). The structure and properties of PEDOT synthesized by template-free solution method. Nanoscale Research Letters. 9(1): 557 